\title{
Análise do composto de marketing em empresas de turismo: um estudo bibliométrico
}

\author{
Analysis of the marketing mix in tourism companies: a bibliometric \\ study
}

\section{Análisis del compuesto de marketing en empresas de turismo: un estudio bibliométrico}

\section{Newton da Silva Miranda Júnior}

Doutorando em Administração (Universidade de Brasília - UnB)

Mestre em Economia (Universidade de Brasília - UnB)

newtondasmjr@gmail.com

Pedro Henrique Rodrigues de Sousa

Doutorando em Administração (Universidade de Brasília - UnB)

Mestre em Administração (Centro Universitário Alves Faria - UNIALFA)

phsousa.adm@gmail.com

\author{
Gisela Demo \\ Docente no Programa de Pós-Graduação em Administração (PPGA-UnB) \\ Doutora em Psicologia Social, do Trabalho e das Organizações (UnB) \\ giselademo@gmail.com
}

Data de submissão: 20/10/2017 - Data de aceite: 03/04/2018

\begin{abstract}
Resumo: Essa pesquisa bibliométrica analisou a produção acadêmica acerca do composto de marketing em empresas atuantes no turismo, no período de 2012 a 2017. O objetivo do artigo foi identificar tendências nos aspectos metodológicos, nas variáveis do composto de marketing e nos segmentos do trade turístico. A quantidade de estudos analisada foi igual a 40 artigos, dos quais 23 foram encontrados em periódicos internacionais e 17 em nacionais. Quanto à análise dos dados coletados, empregou-se estatística descritiva e multivariada por meio de análise categórica de correspondência. Conforme os resultados encontrados, constatou-se que os estudos internacionais recorrem a procedimentos e técnicas
\end{abstract}


quantitativas de investigação, ao passo que os estudos nacionais recorrem aos qualitativos. Também foi notado que, a partir de 2015, houve diminuição na quantidade de estudos publicados referentes ao composto de marketing entre as pequenas e médias empresas atuantes no turismo. A comunicação foi a variável mais recorrente e o preço foi a menos frequente. Com bases na análise categórica de correspondência, a hotelaria foi associada às questões de empreendedorismo e de marketing digital; os setores de alimentação e as agências de turismo às estratégicas de marketing; o setor de recreação e diversão ao marketing de relacionamento; e os demais setores à inovação e à vantagem competitiva. Palavras-chave: Marketing Turístico; Pequenas e Médias Empresas; Bibliometria.

Abstract: This bibliometric research analyzed academic production on the marketing mix in tourism companies during the period 2012 to 2017. The aim of this article was to identify trends in the methodological aspects, in the variables of marketing mix, and in the segments of the tourism trade. A total of forty studies were analyzed; 23 found in international journals and 17 found in national journals. For the analysis of the data collected, descriptive and multivariate statistics were used, through categorical correspondence analysis. Based on the results, it was noted that the international studies used quantitative research procedures and techniques, while the national studies used qualitative methods. It was also noted that from 2015 onwards, there was a decrease in the number of published studies published on the marketing mix in small and medium-sized tourism companies. Communication was the most frequent variable, and price was the least frequent. Based on the categorical analysis of correspondence, the hotel industry was associated with issues of entrepreneurship and digital marketing; the food industry and tourism agencies were associated with marketing strategies; the recreation and leisure industry with relationship marketing; and the other sectors with innovation and competitive advantage. Keywords: Tourism Marketing; Small and Medium-Sized Enterprises; Bibliometry.

Resumen: Esta investigación bibliométrica analizo la producción académica acerca del compuesto de marketing en empresas actuantes en el turismo, en el período de 2012 a 2017. El objetivo del artículo fue identificar tendencias en los aspectos metodológicos, en las variables del compuesto de marketing y en los segmentos del trade turístico. La cantidad de estudios analizados fue igual a 40 artículos, de los cuales 23 fueron encontrados en periódicos internacionales y 17 en nacionales. Cuanto al análisis de los datos recogidos, se empleó estadística descriptiva y multivariada por medio del análisis categórico de correspondencia. Conforme los resultados encontrados, se constató que los estudios internacionales recurren a procedimientos y técnicas cuantitativas de investigación, al cual los estudios nacionales recurren a los cualitativos. También fue notado que, a partir de 2015, hubo diminución en la cantidad de estudios publicados referentes a compuesto de marketing entre las pequeñas y medianas empresas actuantes en turismo. La comunicación fue la variable más recurrente y el precio fue al menos frecuente. Con base en el análisis categórico de correspondencia, la hotelería fue asociada a las cuestiones de emprendedorismo y de marketing digital; los sectores de alimentación y las agencias de turismo a las estrategias de marketing; el sector de recreación y diversión al marketing de relaciones; y los demás sectores a la innovación y a la ventaja competitiva. Palabras clave: Marketing Turístico; Pequeñas y Medianas Empresas; Bibliométrica.

\section{Introdução}

A importância das pequenas e médias empresas - PMEs para o cenário econômico é evidenciado tanto em estudos internacionais quanto nacionais. No que diz respeito ao setor econômico do turismo, essas empresas de menores portes são responsáveis pela oferta de grande parte dos produtos turísticos (Cosma, Paun, Bota, \& Fleseriu, 2014; Oliveira \& Felizola, 2012) eminentemente em forma de prestação de serviços (Souza \& Kovacs, 2009).
O marketing como ferramenta para a competitividade dos destinos pode auxiliar na organização e na estruturação dos produtos e dos serviços turísticos, assim como na atração de turistas, alavancagem da marca, alcance e manutenção de melhores posições de mercado, promoção do destino turístico, entre outros benefícios (Brasil, 2007; Chen \& Mathews, 2014; Firat, Turker, \& Metin, 2014; Santos \& Santos, 2011; Teixeira, 2007). A depender da ênfase mercadológica, essas ferramentas relacionamse a produto, preço, praça ou promoção: os difundidos 4Ps do marketing (McCarthy, 1960). 
Apesar da importância das PMEs ao turismo, sabe-se que são organizações que enfrentam restrições técnicas e financeiras (Chen \& Mathews, 2014), o que pode limitar a implementação dos 4Ps de marketing. Por exemplo, há indícios de baixa produção acadêmica acerca de canais de distribuição no turismo e, dentro da existente, os trabalhos concentram-se em áreas específicas do trade turístico, conforme revisão bibliográfica realizada por Zagheni e Luna (2011). Em consonância com a produção literária mais recente, quais variáveis do composto de marketing, o chamado marketing mix, são mais empregadas e qual o componente do trade turístico em destaque entre empresas de pequeno e médio portes?

O objetivo geral do presente estudo foi analisar a produção científica internacional e nacional relativa aos elementos do marketing mix adotados em pequenas e médias empresas do trade turístico. Por trade turístico, entende-se "o conjunto de agentes, operadores, hoteleiros e demais prestadores de serviços turísticos" (Brasil, 2007, p. 19), tais como acomodações, restaurantes, centros recreativos, souvenir shops, etc. (Awang, Aziz, \& Samdin, 2012). Fica evidente, dessa maneira, que o turismo é uma atividade multifacetada e multidimensional, podendo ser analisado sob diversas óticas (Marujo, 2013).

$\mathrm{O}$ artigo encontra-se estruturado da seguinte maneira: inicialmente é apresentado o referencial teórico envolvendo as pequenas e médias empresas nos contextos de turismo e marketing. $\mathrm{Na}$ seção metodológica, apresentam-se os procedimentos de varredura e os critérios de seleção dos artigos acadêmicos. $\mathrm{Na}$ sequência, são apresentados e discutidos os resultados. Por último, encontramse as considerações finais acerca dos achados do estudo, tendo como norte os questionamentos de pesquisa.

\section{Marketing e trade turísticos em pequenas e médias empresas}

Considerado um dos mais importantes setores econômicos da atualidade (Niedersberg \& Mondo, 2016), o turismo engloba inúmeras atividades, que compõem o denominado trade turístico, composto por meios de hospedagem, bares, restaurantes, agências de viagens, empresas de transporte, lojas de souvenirs, centros de convenções, feiras de negócios e outras atividades relacionadas de modo direto ou indireto à atividade turística (Awang et al., 2012).
As estratégias de marketing podem alavancar o desempenho das organizações que atuam no trade turístico (Sarquis, Pizzinatto, Giuliani, \& Pontes, 2015), sobremaneira aquelas de pequeno e médio portes (Cosma et al., 2014). Entre as contribuições proporcionadas pelo marketing ao turismo, citamse: promoção de destinos turísticos, atração de turistas, segmentação de mercado, diferenciação competitiva, posicionamento de marca e de mercado, personalização da oferta, criação de nichos, assim como outras ligadas às variáveis do marketing mix: produtos ou serviços, preço, promoção e praça (Jaafar, Aziz, \& Sukarno, 2012; Pechlaner, Herntrei, Pichler, \& Volgger, 2012; Chen \& Mathews, 2014; Sarquis et al., 2015).

A proposta conceitual do marketing mix foi difundida por McCarthy (1960), que apresentou os quatrograndesgrupos de atividadesque estruturariam o composto de marketing, ramificado nas variáveis: produto, preço, comunicação e distribuição. McCarthy (1960) sugeriu que estas quatro variáveis fossem exploradas pelas organizações, no intuito de alcançarem os seus objetivos mercadológicos e atraírem mais consumidores.

Os produtos turísticos são compostos majoritariamente pela prestação de serviços e podem ser analisados sob a ótica da oferta e da demanda. Pela perspectiva da oferta, o produto turístico pode ser entendido como o conjunto de atrativos, equipamentos e serviços disponibilizados de modo organizado em certa localidade e por um determinado preço (Brasil, 2007). Pelo lado da demanda, pode ser visto como um bem ou serviço que os consumidores necessitam ou desejam usufruir (Ahmad \& Saber, 2015). Devido à natureza intangível, "o consumidor não pode experimentar os produtos e serviços turísticos antes de consumi-los" (Brasil, 2007, p. 18), isto é, não se pode usufruir deles antes da efetiva utilização (Chen \& Mathews, 2014).

O preço, no marketing mix, está relacionado à capacidade de gerar lucro e atrair consumidores para realizar compras dos produtos e serviços oferecidos pela indústria hoteleira (Ahmad, 2015), por exemplo. A escolha da estratégia adotada pelas pequenas e médias empresas do turismo implica a definição de uma posição em preço e qualidade, na qual o nível de qualidade é o fator que mais implica o nível adotado de preços (Firat et al., 2014). Dessa forma, uma boa estratégia de posicionamento de marketing considera as variáveis de promoção, preço, lugar e produto (Adi, 2015). 
A promoção, também denominada de comunicação, permite que a oferta das empresas do trade turístico encontrem a demanda de potenciais consumidores: à medida que esses passam a conhecer a oferta do produto ou serviço, por outro lado possibilita que as empresas os alcancem (Oliveira \& Felizola, 2012) por meio de sua comunicação integrada de marketing (Ahmad \& Saber, 2015). Por sua vez, os canais de distribuição devem oferecer produtos de forma conveniente à localização (Ahmad \& Saber, 2015), contribuindo de forma significativa à competitividade das empresas no setor do turismo (Barbosa, 2014).

A praça corresponde aos canais de distribuição. Com o advento da Internet e sua difusão global, a distribuição de informação se tornou possível para qualquer pessoa que esteja conectada a ela (Mbatha, 2013). Embora em algumas regiões ainda prevaleça as técnicas boca a boca, por meio de guias ou de agências de turismo (Jaafar, 2012), outras iniciativas já adotam a Internet como um meio para aumentar os canais de distribuição (Abou-Shouk, Lim, \& Megicks, 2012; Ahmad \& Saber, 2015; Zaidan, 2016). No Brasil, os pesquisadores têm recentemente investido nos estudos que exploram os canais eletrônicos de distribuição como ferramenta de marketing para ampliar seus negócios (Barbosa, 2014; Corrêa, 2014).

O marketing turístico deve atuar como um meio para o desenvolvimento regional e para possibilitar que o turismo contribua para o alcance dos objetivos estratégicos dos destinos (Adi, 2015)hotels and restaurants. There are substantial numbers of small medium enterprises (SME. Isso destaca a responsabilidade do estado, de quem o setor turístico é altamente dependente, na implementação de ações para assegurar o desenvolvimento de produtos e atividades turísticas adequadas à eficiente atração de turistas (Jaafar et al., 2012), no intuito de beneficiar, em contrapartida, as pequenas e médias empresas (Ahmad \& Saber, 2015).

\section{Procedimentos metodológicos}

A fim de se alcançar o objetivo proposto nesse estudo, optou-se por uma pesquisa de abordagem qualitativa, utilizando a pesquisa bibliométrica como método. A bibliometria é um método recomendado para análise de produção científica, uma vez que permite traçar um panorama do comportamento e do desenvolvimento de uma área de conhecimento (Araújo \& Alvarenga, 2011). A coleta de dados abrangeu a produção acadêmica do período de 2012 a 2017 e estatística descritiva e multivariada para sua respectiva análise.

Justifica-se esse período pela tentativa de analisar as tendências no campo de estudo entre PMEs orientadas ao mercado apresentadas na vasta revisão de literatura realizada por Shah, El-Gohary e Hussain (2015), a qual englobou o período de 1990 a 2013. Contudo, diferentemente da revisão de literatura desses autores, na presente bibliometria foram considerados apenas artigos de cunho teórico-empírico revisados por pares. Artigos teóricos, bibliometrias, historiografias, casos de ensino e ensaios teóricos não foram computados. Ademais, estudos baseados na perspectiva de turistas ou comportamento do consumidor também não foram incluídos, haja vista que o escopo do presente estudo recai sobre estudos a partir da visão gerencial.

Como fonte de artigos, as varreduras foram realizadas nas bases de dados acadêmicas: Web of Science, Scopus, EBSCOhost, Science Direct, Wiley, Sage, ProQuest, Scielo, Spell e a "Publicações de Turismo". Para a pesquisa de artigos utilizou-se a combinação de termos em duas estratégias de busca. Na primeira varredura nas bases Web of Science, Scopus, EBSCOhost, Science Direct, Wiley, Sage e ProQuest, foram combinados os termos "marketing", "small and medium enterprises" e "tourism" (Estratégia de busca I). Na segunda estratégia de busca nessas bases, foram combinados os termos "marketing", "SME" e "tourism" (Estratégia de busca II), sendo a sigla SME uma abreviação para Small and Medium Enterprise.

Nas bases Scielo e Spell foram empregados somente os termos "marketing" e "turismo", considerando o pequeno volume de artigos encontrados quando se empregavam as estratégias descritas anteriormente. Ou seja, quando se combinavam na busca termos referentes ao porte das organizações, tais como "pequenas e médias empresas", "pequeno porte", "PME" e seus derivados, o quantitativo encontrado era pequeno. Optou-se, dessa forma, por incluir todos os artigos encontrados na busca sem levar em consideração, nessa etapa, o porte das organizações.

Embora o buscador "Publicações de Turismo" não seja uma base ideal de busca, haja vista a desatualização da página desde 2015, recorreuse a ela de forma a complementar os achados nas bases Scielo e Spell. Nessa base, que disponibiliza 
artigos de periódicos científicos de turismo, empregou-se somente o termo "marketing" no buscador, por motivos idênticos aos descritos anteriormente. Ao se inserir termos relativos ao porte das organizações na busca, poucos artigos eram encontrados. Dessa forma, optou-se por incluir todos os artigos encontrados na busca, postergando-se a decisão de incluir ou não o artigo nas análises do presente estudo para a etapa de leitura dos resumos.

Os critérios de busca e a quantidade encontrada de artigos em cada uma das bases de dados consultadas encontram-se na Tabela 1. Somandose o quantitativo de artigos obtidos pelas estratégias de busca I e II quanto à produção internacional e à produção nacional, chegou ao total de 270 publicações. Todavia, restava eliminar as duplicações encontradas dentro de cada base de dados.

Dentro das bases Scielo, Spell e "Publicações de Turismo" não foram encontradas duplicações, haja vista que apenas uma estratégia de busca foi realizada nelas, conforme mencionado anteriormente. Contudo, quando cruzados os resultados obtidos em cada uma dessas bases, muitos artigos se repetiram e, por esse motivo, foi necessário eliminar as duplicações.

Ao total, restaram 165 artigos passadas as etapas de i) eliminação de duplicações dentro de cada base internacional e de ii) eliminação de duplicações entre as diferentes bases nacionais. Não obstante, ao se compilar os artigos provenientes das diferentes bases internacionais, foram encontradas 50 duplicações entre elas, as quais também foram eliminadas. Findada essa etapa de detectar duplicações, os artigos foram filtrados em termos de quantidade de citações recebidas e qualidade de seus periódicos. Para tanto, recorreu-se ao fator de impacto dos artigos internacionais e a avaliação Qualis/Capes dos nacionais.

O fator de impacto utilizado foi o indicador SJR elaborado pelo portal Scimago Journal \& Country Rank, que mede a influência científica de revistas de modo quantitativo e qualitativo. Ou seja, trata-se de um indicador que considera tanto o número de citações recebidas pelas revistas, quanto a qualidade dessas citações, as quais são avaliadas pelo prestígio das revistas que as citam (SCImago, 2007). A avaliação Qualis/Capes, por seu turno, trata de um conjunto de procedimentos que classificam a produção intelectual, por meio da avaliação de periódicos científicos, em oito estratos distintos em consonância com a área de conhecimento: A1, A2, B1, B2, B3, B4, B5 e C (CAPES, 2014).

Conforme discutido no estudo de Ruiz, Greco \& Braile (2009), o fator de impacto de publicações científicas é uma ferramenta acadêmica importante e influente nos meios editorial, acadêmico e científico. Segundo esses autores, o fator de impacto de um determinado período reflete a qualidade dos estudos publicados nele em termos de retidão científica. A estratificação de periódicos nacionais e internacionais pela Capes também

Tabela 1 - Critérios de busca de artigos e o total encontrado nas bases de dados

\begin{tabular}{|c|c|c|c|}
\hline \multicolumn{2}{|c|}{ Base de dados } & Critérios de busca & $\begin{array}{c}\text { Total de artigos } \\
\text { encontrados }\end{array}$ \\
\hline \multirow{4}{*}{ Internacional } & Web of Science & TÓPICO & 65 \\
\cline { 2 - 4 } & Scopus & TITLE-ABS-KEY & 30 \\
\cline { 2 - 4 } & EBSCO & ABSTRACT & 5 \\
\cline { 2 - 4 } & Science Direct & TITLE-ABS-KEY & 15 \\
\cline { 2 - 4 } & Wiley & ABSTRACT & 2 \\
\cline { 2 - 4 } & Sage & ABSTRACT & 6 \\
\cline { 2 - 4 } & ProQuest & RESUMO & 21 \\
\hline
\end{tabular}


pode ser utilizada como indicador de qualidade científica, sendo que os periódicos são avaliados quanto à periodicidade, ao conteúdo científico representativo, à qualificação do corpo editorial, entre outros fatores (Ruiz et al., 2009).

No presente estudo optou-se por não considerar artigos internacionais publicados em periódicos científicos sem fator de impacto, conforme indicador SJR. Dessa forma, foram desconsiderados 14 estudos. Entre os nacionais, embora houvesse a intenção de não se considerar artigos publicados em periódicos sem classificação em algum estrato Qualis/Capes, toda a produção encontrada possuía classificação em algum estrato em relação à área de administração pública e de empresas, ciências contábeis e turismo. Até essa etapa havia 91 artigos remanescentes entre o levantamento acadêmico nas bases.

A etapa subsequente consistiu na leitura dos resumos dos estudos encontrados com o intuito de se verificar o alinhamento deles com o objetivo proposto nesse estudo. Para tanto, três aspectos deveriam estar simultaneamente presentes: i) relação com a área de turismo; ii) referência a algum elemento integrante do composto de marketing (marketing mix); iii) perspectiva de estudo a partir da visão de empresários ou gerentes de empresas ligadas ao turismo. No que tange ao porte dos empreendimentos, em grande parte dos resumos não havia essa informação. Assim, decidiu-se aplicar esse filtro na etapa subsequente de leitura dos artigos na íntegra. Essa etapa foi finalizada com 66 artigos. Após a leitura integral dos artigos, chegou-se ao quantitativo final de 40 artigos, os quais foram analisados no presente estudo. A Figura 1 esquematiza os procedimentos empregados no levantamento da produção acadêmica em consonância ao escopo desse estudo.

Após a varredura da produção acadêmica nacional e internacional, recorreu-se à estatística descritiva - por meio do uso de frequências - e a estatística bivariada - o teste qui-quadrado de Pearson $\left(x^{2}\right)$ - a fim de se retratar os estudos levantados metodologicamente e em relação à distribuição entre as variáveis do marketing mix (produto, promoção, praça e preço), bem como

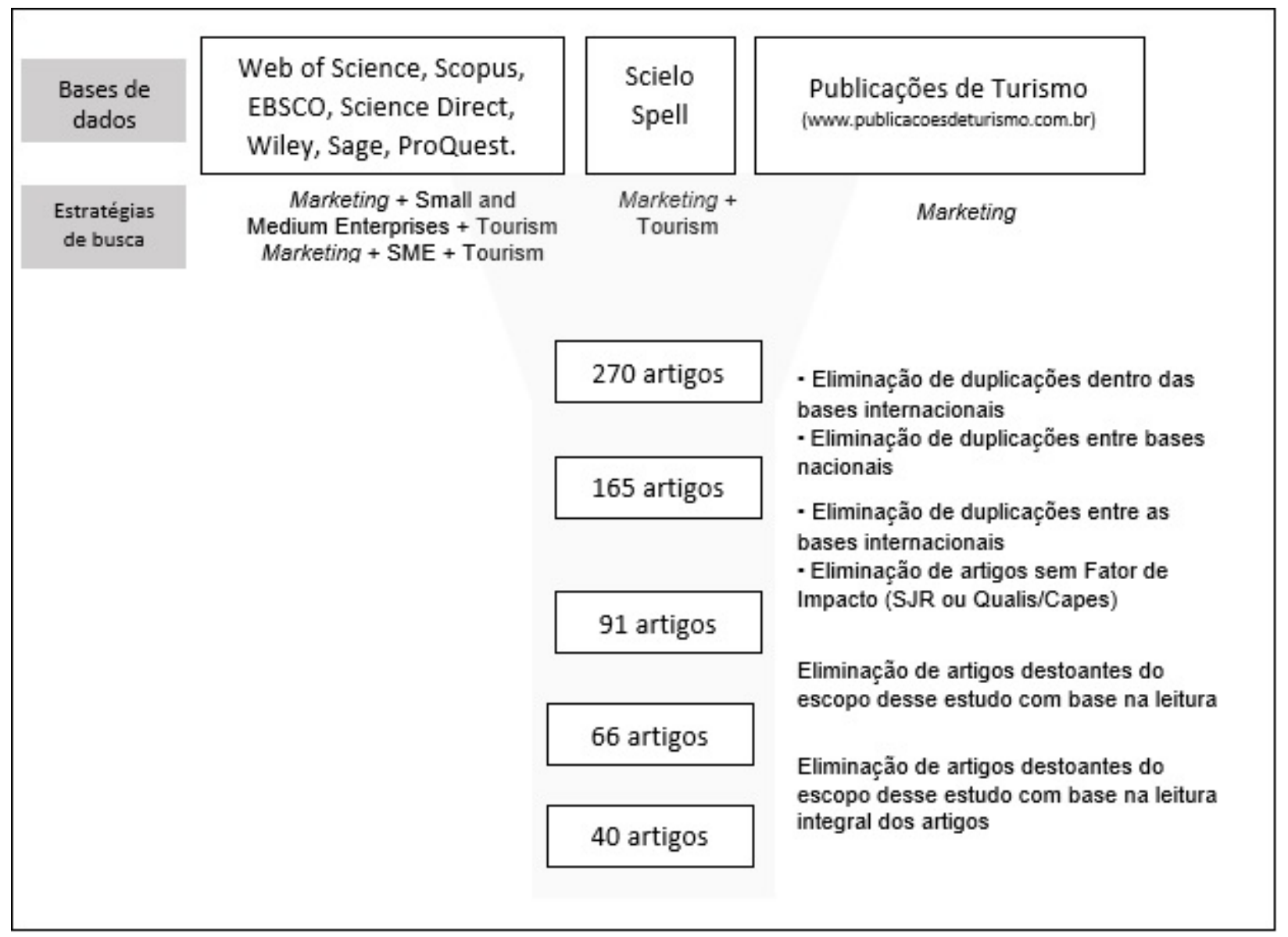

Figura 1 - Procedimentos empregados de levantamento da produção acadêmica Fonte: Elaborada pelos autores 
verificar possíveis associações entre variáveis. O teste estatístico do qui-quadrado de Pearson é recomendado quando se busca avaliar se duas variáveis categóricas encontram-se, de alguma maneira, relacionadas entre si, o que pode ser evidenciado quando a significância é p-value < 0,05 (Field, 2009). Respectivamente, as seguintes perguntas de pesquisa nortearam as análises: Quais as diferenças metodológicas entre as produções acadêmicas internacionais e nacionais acerca do marketing turístico entre pequenas e médias empresas? Quais as variáveis do marketing mix mais abordadas pela produção acadêmica levantada?

No intuito de verificar a existência de correspondência entre os temas utilizados no embasamento teórico dos estudos e os respectivos setores econômicos do trade turístico aos quais faziam alusão, recorreu-se à estatística multivariada da análise correspondência ANACOR. Essa técnica visa medir o grau de associação de variáveis categorizadas dispostas em tabelas de contingência, sugerida quando $p$-value $<0,05$ (Hair, 2010). Nessa etapa, a pergunta de pesquisa foi: Existe correspondência categórica entre o referencial teórico (teorias utilizadas) e o tipo de área econômica do turismo abordada nos estudos levantados? Recorreu-se ao software SPSS 20 (Statical Package for Social Science) na realização dos testes estatísticos.

\section{Resultados e discussões}

Nesta seção serão apresentadas: a identificação demográfica da produção acadêmica internacional e nacional levantadas, a distribuição da produção acadêmica em relação às variáveis do composto de marketing e as correspondências entre as teorias utilizadas pelos estudos e os respectivos setores econômicos a que se referem dentro do trade turístico.

\section{Identificação e demografia da produção acadêmica levantada}

Da totalidade de artigos analisados no presente estudo, 23 foram publicados em periódicos de âmbito internacional, os quais se encontram listados no Quadro 1, por ordem alfabética, a partir do título do artigo. Entre esses estudos, os autores com maior produção foram: Mohamed Abou-Shouk, Phil Megicks e Wai Min Lim, cada qual com 2 publicações. A produção científica foi dispersamente publicada entre 21 periódicos diferentes, aproximando-se da correspondência de quase um periódico para cada artigo. Os periódicos International Journal of Entrepreneurship and Small Business e Tourism Management foram os que mais publicaram, embora sem expressividade quantitativa em relação aos demais: cada um publicou dois artigos entre os levantados.

Quadro 1 - Produção científica internacional levantada

\begin{tabular}{|c|c|}
\hline Título do artigo, autoria e ano & Periódico \\
\hline $\begin{array}{l}\text { Analysis of ICT usage patterns, benefits and barriers in tourism SMEs in the } \\
\text { Middle Eastern countries (Zaidan, 2016) }\end{array}$ & $\begin{array}{l}\text { Journal of Vacation } \\
\text { Marketing }\end{array}$ \\
\hline $\begin{array}{l}\text { Building a Facebook Strategy: Some Insights From Australian } \\
\text { Accommodation Small Tourism Enterprises - STEs (Mizrachi \& Sellitto, } \\
\text { 2015) }\end{array}$ & $\begin{array}{l}\text { Journal of Quality } \\
\text { Assurance in Hospitality } \\
\text { and Tourism }\end{array}$ \\
\hline $\begin{array}{l}\text { Does the adoption of customer and competitor orientations } \\
\text { make small hospitality businesses more entrepreneurial? Evidence from } \\
\text { Kazakhstan (Seilov, 2015) }\end{array}$ & $\begin{array}{c}\text { International Journal of } \\
\text { Contemporary Hospitality } \\
\text { Management }\end{array}$ \\
\hline $\begin{array}{l}\text { Entrepreneurial marketing and accommodation businesses in East Peninsular } \\
\text { Malaysia (Jaafar, 2012) }\end{array}$ & $\begin{array}{l}\text { Journal of Research } \\
\text { in Marketing and } \\
\text { Entrepreneurship }\end{array}$ \\
\hline $\begin{array}{l}\text { Entrepreneurship and social media marketing: Evidence from French small } \\
\text { business (Nakara, Benmoussa, E Jaouen, 2012) }\end{array}$ & $\begin{array}{l}\text { International Journal of } \\
\text { Entrepreneurship and } \\
\text { Small Business }\end{array}$ \\
\hline
\end{tabular}


Exploring the potential of electronic commerce tools in South African SME tourism service providers (Mbatha, 2013)together with other ICT enabling technologies, offers a platform for organizations to arrange their business processes, address their marketplaces, and partner with other enterprises. This paper reports on the diffusion and adoption of electronic commerce tools by small and medium enterprise (SME

From destination management towards governance of regional innovation systems - the case of South Tyrol, Italy (Pechlaner et al., 2012)

Innovation - A Useful Tool in the Rural Tourism in Romania (Cosma et al., 2014)

Integrating territory regeneration, culture and sustainable tourism. the italian albergo diffuso model of hospitality (Romolini, Fissi, \& Gori, 2017)

Internet Adoption by Travel Agents: a Case of Egypt (M. Abou-Shouk et al., 2012)

Key successful indicators for small businesses' integrated marketing model (Adi, 2015)hotels and restaurants. There are substantial numbers of small medium enterprises (SME

Methodologies for monitoring website performance: Assessing the effectiveness of AdWords campaigns on a tourist SME website (Moral, Gonzalez, E Plaza, 2014)

Overview of perceptions of German wine tourism from the winery perspective (Koch, Martin, E Nash, 2013)

Patterns of innovation in tourism 'Small and Medium-size Enterprises' (Tejada \& Moreno, 2013)

Social network enterprise behaviors and patterns in SMEs: Lessons from a Portuguese local community centered around the tourism industry (Fernandes, Belo, \& Castela, 2016) and have groups of professionals responsible for these platforms. Most managers perceive that social networks enhance business performance, but few measure the results. Firms that most frequently use social networks have managers with higher qualifications. This study identified two types of social-network use: a

Specification of target market in small and medium scale accomadation businesses: A study on boutique hotels operating in city of mugla (Firat et al., 2014)

Supporting innovation for tourism development through multistakeholder approaches: Experiences from Africa (Carlisle, Kunc, Jones, \& Tiffin, 2013)

The contribution of the Internet to the strategic positioning of small businesses in the tourism industry (Favre-Bonté \& Tran, 2015)

The growth of micro, small, and medium-sized hotel enterprises: the hoteliers' perspectives (Carlisle et al., 2013)
Information Development

Tourism Review

Procedia - Social and

Behavioral Sciences

Tourism Management Perspectives

International Journal of Tourism Research

International Journal of Applied Business and Economic Research

Online Information Review

International Journal of Wine Business Research

Service Industries Journal

Technology in Society

Tourismos

Tourism Management

International Journal of Entrepreneurship and Small Business

Arab World Geographer 
Tourism enterprises beyond the margins: the relational practices of Aboriginal and Torres SMEs in remote Australia (Jacobsen, 2017)

Tourism Marketing: An Overview of Small and Medium Budget Hotels - SMBHs (Jaafar et al., 2012)

Understanding marketing strategies with particular reference to small- and medium-sized hotel businesses in the United Arab Emirates (Ahmad \& Saber, 2015)

Using competing models to evaluate the role of environmental pressures in ecommerce adoption by small and medium sized travel agents in a developing country (M. Abou-Shouk, Lim, \& Megicks, 2016)

\section{Fonte: Elaborado pelos autores}

A variedade de países lócus de pesquisa da produção científica internacional levantada foi igual a 16. Agregados em continentes, os países identificados do continente europeu (43\%) foram: Alemanha, Espanha, França, Itália, Portugal, Romênia, Turquia; do asiático (26\%): Cazaquistão, Emirados Árabes Unidos, Indonésia, Malásia; do africano (22\%): África do Sul, Egito, Gâmbia, Tanzânia e do oceânico (9\%): Austrália.

A produção nacional levantada totalizou 17 artigos, conforme listados no Quadro 2, por
Tourism Planning and Development

Asia Pacific Journal of Tourism Research

Tourism and Hospitality Research

Tourism Management

Quadro 2 - Produção científica nacional levantada

\begin{tabular}{|c|c|}
\hline Título do artigo & Periódico \\
\hline $\begin{array}{l}\text { Estratégias de marketing: Estudo no setor de agências de viagens e } \\
\text { turismo (Sarquis et al., 2015) }\end{array}$ & $\begin{array}{l}\text { Revista Brasileira de Pes- } \\
\text { quisa em Turismo }\end{array}$ \\
\hline $\begin{array}{l}\text { Eventos Gastronômicos e Estratégias de Marketing: O Festival Comida } \\
\text { Di Buteco em Belo Horizonte, MG (Suzuki, Burkowski, \& Mesquita, } \\
\text { 2015) }\end{array}$ & Revista Rosa dos Ventos \\
\hline $\begin{array}{l}\text { Distribuição eletrônica na hotelaria: um estudo de caso do Hotel Casa de Praia, } \\
\text { Fortaleza (CE) (Barbosa, 2014) }\end{array}$ & $\begin{array}{l}\text { Revista Brasileira de Eco- } \\
\text { turismo }\end{array}$ \\
\hline $\begin{array}{l}\text { E-Marketing das Estâncias Hidrominerais do Estado de São Paulo, } \\
\text { Brasil (Corrêa, 2014) }\end{array}$ & Turismo em Análise \\
\hline $\begin{array}{l}\text { A percepção dos gestores quanto às práticas sustentáveis implantadas em meios } \\
\text { de hospedagem de pequeno porte (Rossetto, 2014) }\end{array}$ & $\begin{array}{l}\text { Revista de Turismo Con- } \\
\text { temporâneo }\end{array}$ \\
\hline $\begin{array}{l}\text { Implementação de ações inovadoras e empreendedorismo: estudo de múltiplos } \\
\text { casos em empresas hoteleiras de pequeno porte (Sacramento \& Teixeira, 2014b) }\end{array}$ & Caderno Virtual de Turismo \\
\hline
\end{tabular}




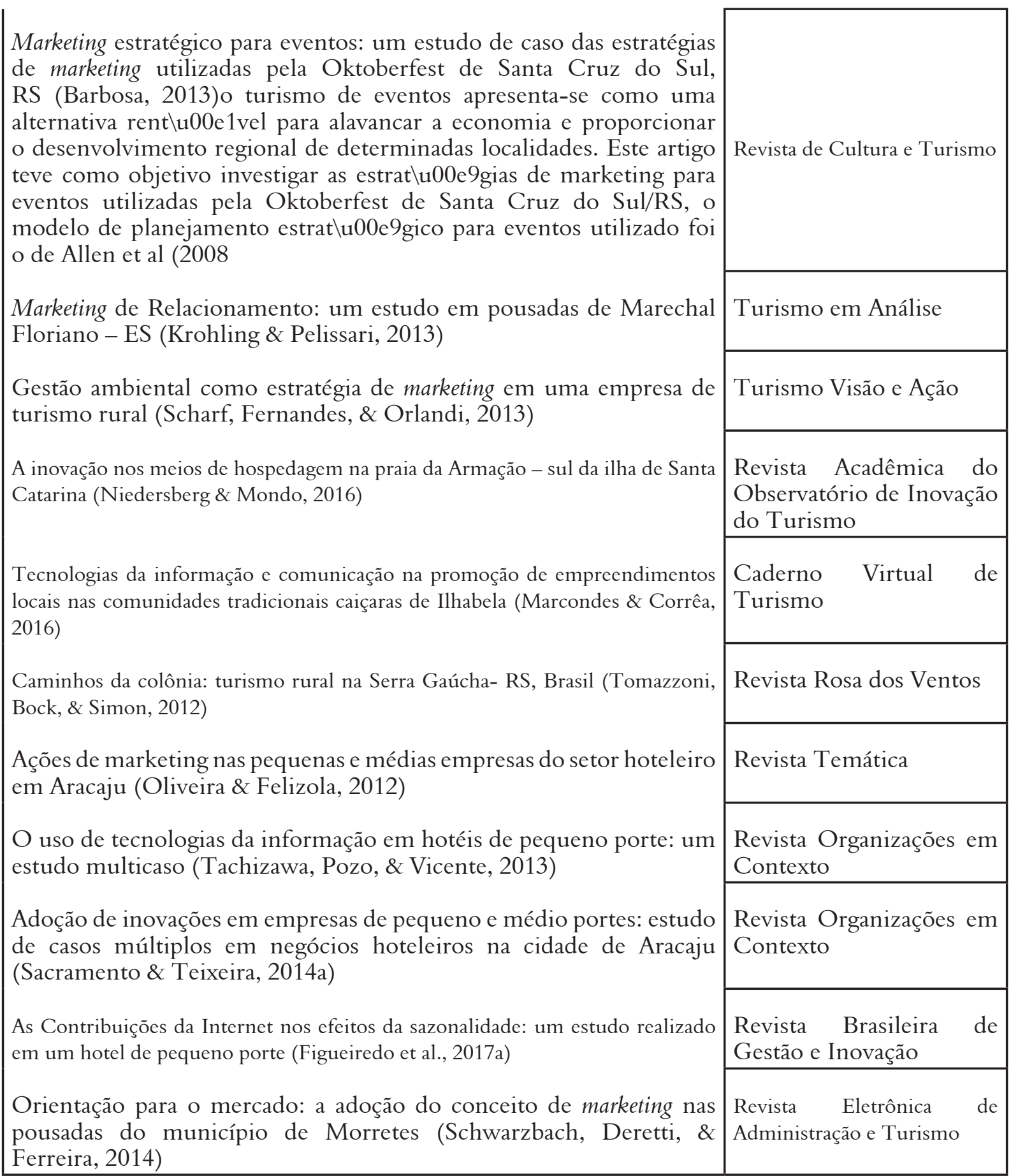

\section{Fonte: Elaborado pelos autores}

A distribuição dos lócus de pesquisa dos estudos nacionais concentrou-se em três regiões geográficas brasileiras: Sul (35\%), entre os estados Santa Catarina, Rio Grande do Sul e Paraná; Sudeste (35\%), entre os estados Minas Gerais, São Paulo, Rio de Janeiro e Espírito Santo; e Nordeste (30\%), pelos estados Ceará, Sergipe e Rio Grande do Norte.

Em geral, predominou nos estudos levantados a quantidade de 3 autores por artigo, com expressividade de $35 \%$. $\mathrm{Na}$ literatura internacional, a maior recorrência foi também de 3 autores por artigo, ao passo que, na nacional, prevaleceu a quantidade de 2 autores por artigo, correspondendo a $30 \%$ da produção levantada. Em relação à produção acadêmica total levantada, a variação máxima de autores por artigo foi igual a $4(13 \%)$ e a mínimo 1 autor (23\%).

A titulação predominante entre os primeiros autores foi o doutorado ou $\mathrm{PhD}(72 \%)$ e, sequencialmente, mestrado (18\%), graduação $(8 \%)$ e especialização (2\%). Salienta-se que 
a frequência de doutores entre os autores internacionais foi unânime, ao passo que na produção nacional foram encontrados autores que, na época da publicação do artigo, possuíam os títulos de mestre e especialista ou estavam na graduação. Dessa forma, tem-se um primeiro diferencial entre a produção internacional e a nacional: ao passo que na primeira a produção é composta por doutores, na segunda a autoria foi contrabalanceada por doutores com mestres, ou especialistas ou graduados. Em relação à área de formação ou atuação dos primeiros autores, Turismo (28\%) e Administração (25\%) foram as mais recorrentes, sendo as demais: Economia (13\%), Gestão Estratégia (13\%), Comunicação Social (10\%), Engenharia (5\%), Geografia (5\%) e Ciências Sociais (3\%).

Em relação à distribuição dos artigos por ano de publicação, no período de 2012 a 2017, a maior expressividade de publicações, tanto internacionais quanto nacionais, ocorreu nos anos de 2013 e 2014, sendo o pico de publicações igual a 9 artigos em cada um desses anos. No período de 2012 a 2014, ao passo que as publicações internacionais diminuíram, as nacionais cresceram. A partir de 2015, contudo, percebeu-se uma diminuição na quantidade de artigos publicados, tanto em âmbito internacional quanto nacional. A Figura 2 informa a distribuição das publicações ao longo do período considerado nesse estudo.

Por sua vez, o trade turístico foi construído pela leitura dos artigos levantados e a identificação da área econômica do turismo abordada por eles, tendo como base a publicação do Ministério do Turismo (Brasil, 2007). Ao todo, chegou-se a uma variedade de 5 setores econômicos, sendo um deles residual. Esse residual, denominado como "atividades diversificadas", abrangeu os estudos que não se referiram a uma determinada área, mas sim à indústria do turismo, a exemplo dos estudos internacionais de Nakara et al. (2012), Mbatha (2013), Adi (2015) e dos nacionais realizados por Oliveira e Felizola (2012) e Marcondes e Corrêa (2016). Em ordem decrescente de expressividade, os setores econômicos do trade turístico identificados foram: meios de hospedagens (49\%), atividades diversificadas (26\%), agências de viagens (11\%), restaurantes e bares - ramo de alimentação (7\%) e empresas ligadas às atividades recreativas, culturais e desportivas do turismo (7\%).

\section{Tipificação metodológica da produção acadêmica}

É sabido que, conforme sublinha Marujo (2013), o turismo é caracterizado por ser um fenômeno multidimensional, o que possibilita análises sob diversos pontos de vista. Em relação aos enfoques de investigação, tanto na literatura internacional quanto na nacional (analisados de maneira agregada) houve predominância do enfoque qualitativo (45\%) em comparação ao enfoques quantitativo (40\%) e misto (15\%). Considerando-se somente os internacionais, prevaleceu o enfoque quantitativo (53\%), ao passo que nos nacionais foi o enfoque qualitativo $(70 \%)$. Por sua vez, o enfoque misto foi o menos

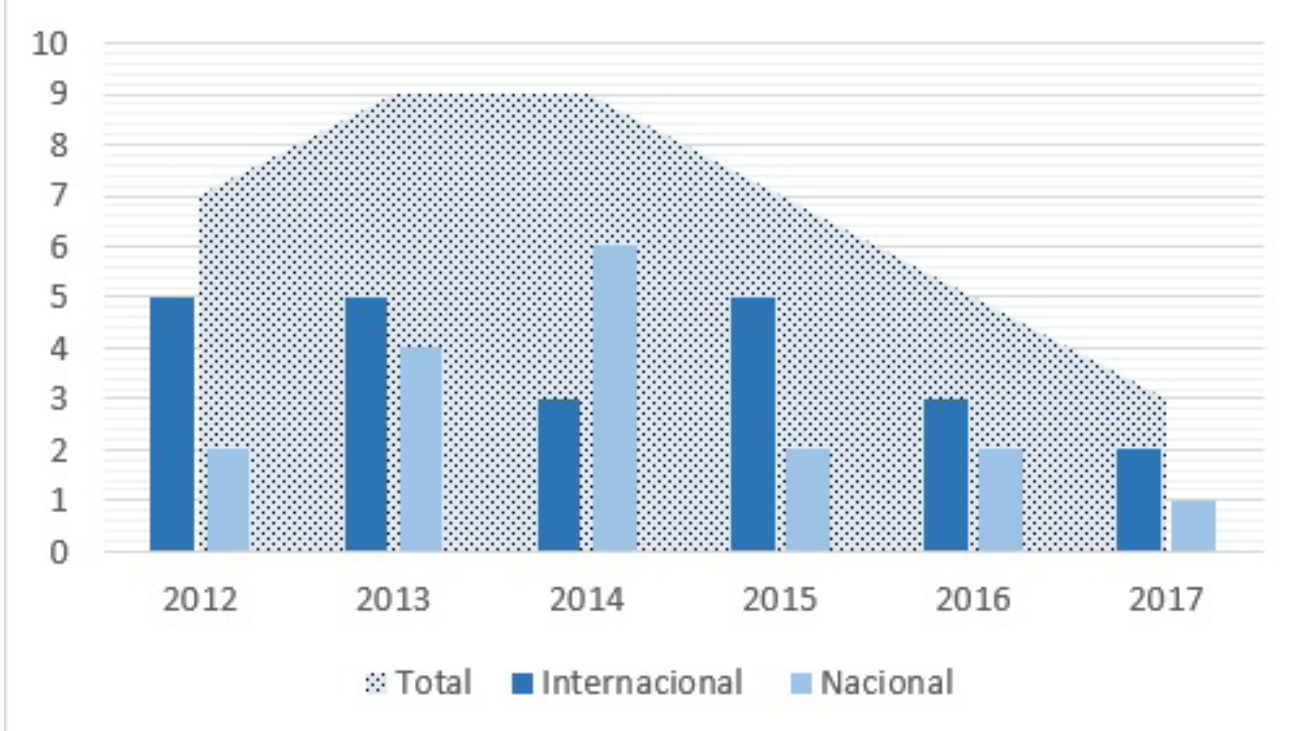

Figura 2 - Distribuição dos artigos por ano de publicação

Fonte: Elaborada pelos autores. 
expressivo em ambos casos: $21 \%$ na produção internacional e $6 \%$ na nacional.

Segundo Sampieri, Fernández e Baptista (2010), o enfoque qualitativo é caracterizado pela utilização de dados não numéricos no processo de interpretação do fenômeno, ao passo que o enfoque quantitativo busca provar hipóteses com base em medição numérica e instrumentos estatísticos de análise. Ainda segundo aqueles autores, a combinação de ambos enfoques num estudo caracteriza-o como misto, o que é desejável nas investigações na área de Turismo (Marujo, 2013).

No intuito de se verificar associação estatística entre os tipos de enfoques de pesquisa em relação ao âmbito internacional ou nacional da produção acadêmica levantada, realizou-se o teste quiquadrado de Pearson $\left(x^{2}\right)$ entre as variáveis categóricas "enfoque de pesquisa" e "âmbito de publicação". O valor do qui-quadrado encontrado foi de $x^{2}=7,945$, com grau de liberdade igual a 2 e significância de $p=0,019$, o que se permite inferir que existe associação estatística significativa entre essas duas variáveis categóricas, sugerindose outra diferença entre a produção internacional e a nacional. Para se verificar a força dessa associação, procedeu-se ao cálculo do coeficiente de contingência. $O$ valor encontrado para esse teste foi de $\mathrm{C}=0,019$, o qual expressa fraca associação entre as variáveis (Field, 2009). É possível se entrever que entre os estudos levantados, embora haja associação entre as variáveis categóricas acerca do tipo de enfoque de pesquisa (qualitativo, quantitativo e misto) e o âmbito de publicação dos estudos (internacional ou nacional), o coeficiente de contingência sinaliza associação fraca entre elas.

Quantoàs demais categorias metodológicasque integraram os desenhos das pesquisas levantadas, predominou o tipo de recorte de estudo transversal (92\%) em relação ao longitudinal $(8 \%)$; a origem primária dos dados $(85 \%)$ em relação à secundária (7,5\%) e Mista (7,5\%); e o método de pesquisa levantamento (45\%) em relação ao estudo de casos múltiplos $(20 \%)$, combinação de métodos $(20 \%)$ e estudo de caso único (15\%). Quanto aos procedimentos e às técnicas de pesquisa, a entrevista (43\%) e o questionário (40\%) foram os instrumentos de pesquisa mais utilizados, seguidos pela combinação de instrumentos (12\%) e pela observação (5\%). Analisando-se o emprego dos instrumentos de pesquisa entre a produção acadêmica internacional e a nacional, percebeu-se a predominância de aplicação de questionário na primeira e a entrevista na segunda.
Vale mencionar que entre os estudos nacionais levantados, em quase metade deles a entrevista foi empregada juntamente com outros procedimentos técnicos ou fontes de informação, tais como: pesquisa bibliográfica, pesquisa documental. Juntamente se empregou também a técnica de coleta de dados da observação. Esses procedimentos, fontes de informação ou técnicas de coleta de dados, foram adotados de modo preliminar como estratégia de familiarização dos pesquisadores com o lócus da pesquisa, a exemplo da pesquisa documental realizada no estudo de Sacramento e Teixeira (2014) e da observação direta em Figueiredo et al. (2017). De outro modo, nos estudos internacionais, com exceção daqueles classificados como enfoque misto, empregou-se apenas um instrumento de pesquisa.

Entre as técnicas analíticas empregadas, a análise de conteúdo (40\%) e as estatísticas descritiva $(35 \%)$ e multivariada (18\%) foram as mais recorrentes, seguidas pela estatística bivariada $(5 \%)$ e pela análise de discurso $(2 \%)$. Foi possível se perceber que a produção internacional se difere da nacional também em relação às técnicas analíticas empregadas: na primeira prevaleceram as técnicas quantitativas, ao passo que na segunda as qualitativas. Havia expectativa em relação a essas diferenças, considerando-se os enfoques de pesquisa predominantes entre os tipos de produções. Vale destacar que as técnicas estatísticas multivariadas foram empregadas somente por estudos internacionais, ao passo que a análise de discurso somente entre os nacionais. A Figura 3 informa a composição na utilização das técnicas analíticas identificadas pelas produções acadêmicas internacional e nacional.

De mesma forma, o tipo de amostragem convergiu com o enfoque de pesquisa, sendo que a amostragem quantitativa (55\%) prevaleceu sobre a qualitativa (42\%) e a Mista (3\%). A distribuição entre as espécies de amostragens quantitativas configurou-se em não probabilística (33\%), probabilística (12\%) e censitária $(10 \%)$. Entre as amostragens qualitativas, a amostragem por múltiplos casos (57\%) superou a amostragem por caso único $(43 \%)$.

\section{Composto de marketing entre pequenas e médias empresas do turismo}

O marketing mix é um composto de elementos controláveis voltados ao mercado cuja implementação objetiva, sobremaneira, atrair 


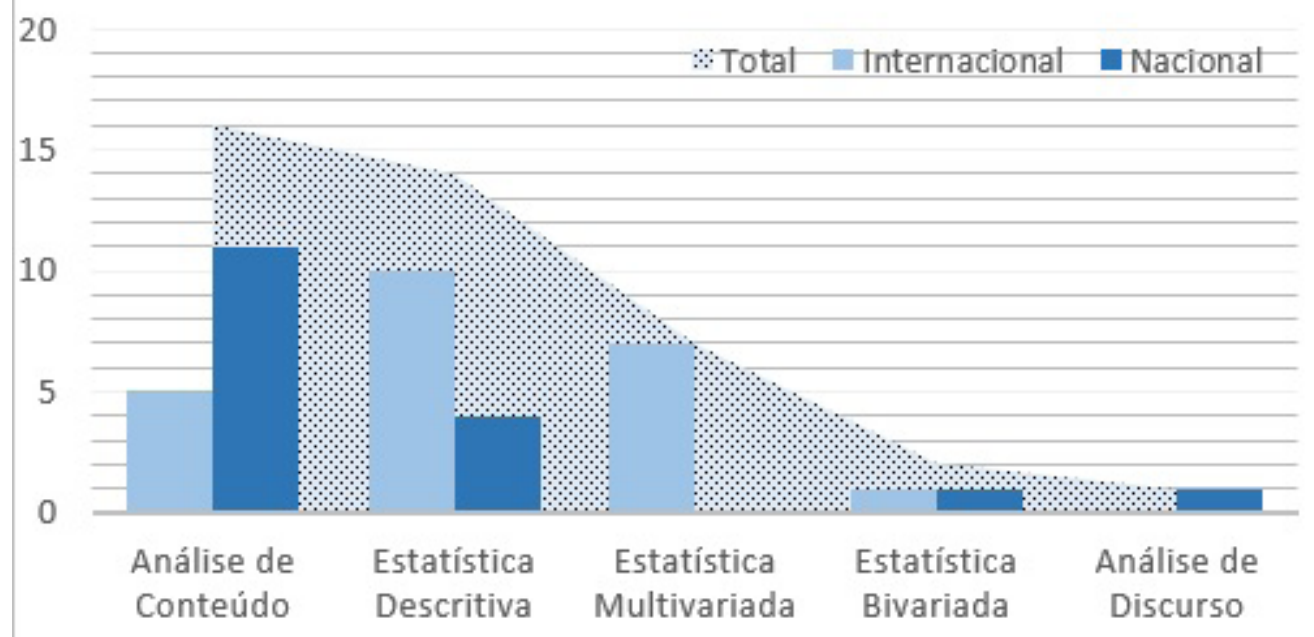

Figura 3 - Técnicas analíticas identificadas

Fonte: Elaborada pelos autores

consumidores (McCarthy, 1960). Segundo esse autor, tais elementos dificilmente são adotados isoladamente, mas sim combinados em estratégias de, por exemplo, posicionamento, produto, preço de venda, promoção (Ahmad \& Saber, 2015), entre outros. O presente estudo corrobora essa constatação, sendo que entre a produção acadêmica total levantada, $80 \%$ englobou dois ou mais elementos do composto de marketing. Dessa forma, vai ao encontro do que enfatiza McCarthy (1960): a importância de que os elementos que constituem o composto de marketing estejam integrados.

Os estudos que abordaram a comunicação $(42 \%)$ como elemento de marketing mix enfatizaram, em grande maioria, as mídias sociais. Trata-se de plataformas especialmente recomendadas para pequenas e médias empresas do turismo, sobremodo aquelas com recursos limitados (Nakara et al., 2012), a fim de obterem visibilidade no cenário global (Marcondes \& Corrêa, 2016), atingindo novos mercados e reduzindo custos (Moral et al., 2014). A importância reside na capacidade delas em fornecer canais de acesso ao mercado (Nakara et al., 2012) e, consequentemente, aos turistas (Mizrachi \& Sellitto, 2015). Nakara, Benmoussa e Jaouen (2012) investigaram as espécies de mídias sociais mais usadas para fins turísticos, constatando-se o Facebook como a mais utilizada, sobremodo em se tratando da promoção de estabelecimentos nacionais (Marcondes e Corrêa, 2016), tendo como justificativa o menor custo de sua implementação (Mizrachi \& Sellitto, 2015).
Os produtos turísticos são formados a partir dos recursos naturais e culturais que integram determinado destino, sendo abordados por $36 \%$ dos estudos levantados. De acordo com Santos e Santos (2011), um produto em turismo é composto por uma parte tangível e outra, predominante, intangível. Os produtos e os serviços turísticos complementam-se (Firat et al., 2014) e, em conjunto com o próprio destino turístico, contribuem para a diferenciação da oferta turística e atração de turistas (Jaafar et al., 2012). Entre os estudos levantados, Firat et al. (2014) analisaram as contribuições de uma espécie de hospedagem turca à indústria do turismo do país. Koch, Martin e Nash (2013) investigaram como o produto vinho poderia induzir ao turismo de uma região alemã.

Os canais de distribuição exercem um importante papel dentro do composto de marketing (Barbosa, 2014). Os estudos que abordaram distribuição como elemento do marketing mix (18\%) deram ênfase à utilização do comércio eletrônico como canal, que, segundo Corrêa (2014), beneficia a indústria turística por meio da prática do comércio em nível global. Além disso, os instrumentos de comércio eletrônico possibilitam o alcance de novos clientes (Mbatha, 2013) e o aumento do volume de vendas (Tachizawa et al., 2013) e, portanto, do volume de receitas (Abou-Shouk, Lim, \& Megicks, 2016). Ademais, os canais de distribuição eletrônicos são importantes mecanismos para a simplificação da distribuição dos serviços prestados pelos hotéis aos clientes (Barbosa, 2014) e podem ser um 
diferencial de competitividade (Tachizawa, Pozo, Vicente, 2013).No presente estudo bibliométrico, houve quantidade pouco expressiva de artigos que abordaram a variável preço (4\%): apenas dois artigos internacionais e um artigo nacional abordaram o assunto. Ahmad \& Saber (2015) explicam que o preço deve atrair cliente para executar compra e gerar lucro para a organização. Sarquis et al. (2015) expuseram que, dentre as organizações estudadas por eles, as agências de viagem de médio porte utilizavam, com maior frequência, estratégias de precificação de serviço no intuito de aumentar as vendas.

\section{Trade e marketing turísticos}

Influenciado pelo estudo bibliométrico de Marsilio e Vianna (2014), em que se constatou a predominância de um tema específico entre os estudos relacionados a um setor econômico definido, buscou-se nessa seção investigar quais as temáticas mais abordadas em cada setor econômico do trade turístico identificado entre os artigos. Para tanto, recorreu-se à análise de correspondência, a qual foi realizada entre as palavras-chave informadas nos artigos, assim como as temáticas identificadas nos referenciais teóricos em relação aos setores econômicos identificados neles. O Quadro 3 informa as palavras-chaves e os temas identificados e as respectivas categorias criadas, nesse estudo, para representá-los.

Ao se relacionar as categorizações, conforme Quadro 3, com os setores econômicos do trade turístico, o valor do qui-quadrado encontrado foi de $x^{2}=49,933$, com grau de liberdade igual a 20 e significância de $\mathrm{p}=0,000$, o que sugere existência de associação entre as linhas e as colunas da tabela de contingência composta pelas categorias formadas e os setores econômicos do trade turístico. A variância total ou inércia total encontrada foi de $70,3 \%$. Isto é, para o modelo elaborado, as categorizações formuladas explicam $70,3 \%$ de algo sobre os setores econômicos identificados do trade turístico e vice-versa. A relação entre essas variáveis categóricas fica aparente por meio do mapa perceptual, com normalização simétrica, representado na Figura 4, em que estão evidenciados 4 agrupamentos. Conforme Hair (2010), a proximidade entre pontos sugere similaridades entre eles, ao passo que a distância sugere dissimilaridades.

As atividades recreativas, culturais e desportivas (RCD), tais como eventos (Barbosa, 2013)o turismo de eventos apresenta-se como uma alternativa rentável para alavancar a economia e proporcionar o desenvolvimento regional de determinadas localidades. Este artigo teve como objetivo investigar as estratégias de marketing para eventos utilizadas pela Oktoberfest de Santa Cruz do Sul/RS, o modelo de planejamento estratégico para eventos utilizado foi o de Allen et al (2008 e festivais gastronômicos (Suzuki et al., 2015), recorrem, conforme sugerido pelo aglomerado I da Figura 4, ao Marketing de Relacionamento. O turismo recreativo, cultural e desportivo cresce gradativamente em todo o mundo (Barbosa, 2013)o turismo de eventos apresenta-se como uma alternativa rent $\backslash u 00 \mathrm{e} 1 \mathrm{vel}$ para alavancar a economia e proporcionar o desenvolvimento regional de determinadas localidades. Este artigo teve como objetivo investigar as estratl

Quadro 3 - Categorização das palavras-chave e temas identificados na produção levantada

\begin{tabular}{|l|l|}
\hline Palavras-chaves ou temas identificados & Categorizações \\
\hline Economia criativa, Empreendedorismo & Empreendedorismo \\
\hline $\begin{array}{l}\text { Estratégia, Segmentação de mercado, Posicionamento } \\
\text { estratégico }\end{array}$ & Estratégia em Marketing \\
\hline Inovação em processo, Inovação em sistemas & Inovação em Marketing \\
\hline Comércio eletrônico, Redes Sociais, Mídia Social & Marketing Digital \\
\hline Relacionamento com consumidores & $\begin{array}{l}\text { Marketing } \\
\text { Relacionamento }\end{array}$ \\
\hline Cooperação, Visão baseada em Recursos & Vantagem Competitiva \\
\hline
\end{tabular}

Fonte: Elaborado pelos autores. 


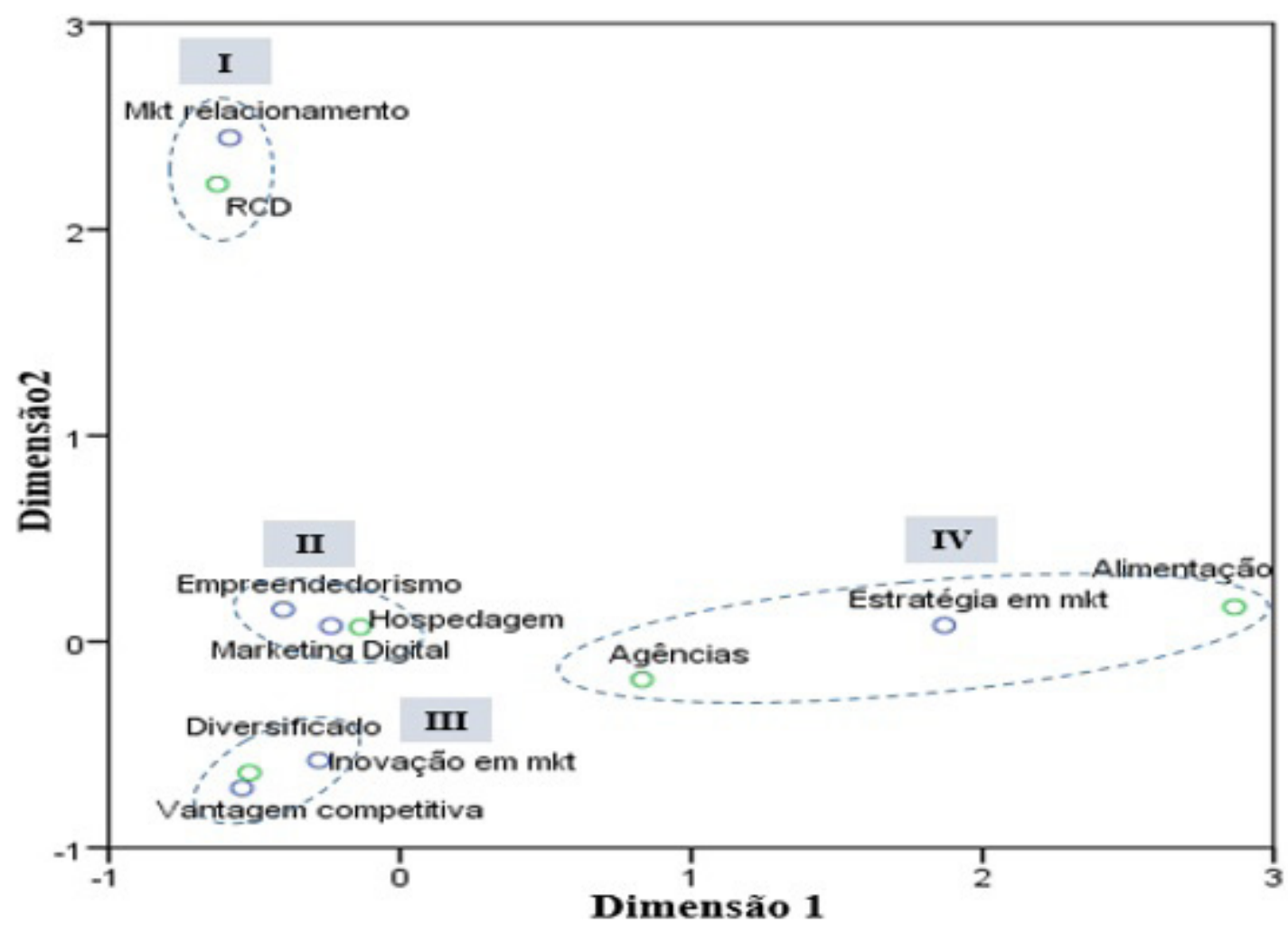

Figura 4 - Mapa perceptual: categorias e trade turístico Fonte: Elaborada pelos autores com auxílio do SPSS

u00e9gias de marketing para eventos utilizadas pela Oktoberfest de Santa Cruz do Sul/RS, o modelo de planejamento estratlu00e9gico para eventos utilizado foi o de Allen et al (2008, sendo imprescindível para ele, em termos de competitividade, acomunicaçãoe orelacionamento com os públicos de interesse (Suzuki et al., 2015). Desse modo, o relacionamento com o consumidor pode ser estabelecido antes mesmo da realização do evento, sendo que a própria programação dele pode ser definida pelo público-alvo (Barbosa, 2013)o turismo de eventos apresenta-se como uma alternativa rent $\mid u 00$ e1vel para alavancar a economia e proporcionar o desenvolvimento regional de determinadas localidades. Este artigo teve como objetivo investigar as estrat $\backslash$ u00e9gias de marketing para eventos utilizadas pela Oktoberfest de Santa Cruz do Sul/RS, o modelo de planejamento estratégico para eventos utilizado foi o de Allen et al (2008. A orientação de marketing centrada no cliente, que é a filosofia de consultar os consumidores antes da produção de bens ou prestação de serviços, pode direcionar as empresas de pequeno porte (Seilov, 2015), contribuindo para atração de diferentes perfis turísticos (Jaafar, 2012).
Os meios de hospedagem encontram-se aglomerados comas categorias Empreendedorismo e Marketing Digital, conforme indicado pela aglomeração II (Figura 4). Segundo Seilov (2015), o empreendedorismo, a inovação e a criatividade são fundamentais ao desenvolvimento econômico do turismo, sobremodo entre as PMEs de hospedagem cujos dirigentes tendem a ser empreendedores (Mizrachi \& Sellitto, 2015). Quanto ao Marketing Digital, a capacidade tecnológica da Internet pode ser um instrumento valioso ao marketing. No setor turístico, a utilização de tecnologias de comunicação torna possível um melhor vínculo com os clientes, melhor legibilidade, e atendimento mais adequado das expectativas dos clientes (Bonillo, Fernandez, \& Taulet, 2012).

O agrupamento III (Figura 4) associou as atividades diversificadas, que se referem à indústria do turismo, com as categorias Inovação em Marketing e Vantagem Competitiva. A presença ou expectativa de cooperação ou outros níveis de relacionamentos interorganizacionais foram ações recorrentemente citadas nesses estudos, tendo como justificativa a capacidade de indução à competitividade (Jacobsen, 2017). Embora a 
cooperação possa ser estabelecida entre empresas pertencentes ao mesmo mercado (Jaafar et al., 2012), nem sempre os empresários, motivados pela competição, desejam cooperar com seus similares (Koch et al., 2013).

As agências de viagens e os estabelecimentos ligados ao ramo de alimentação no mercado turístico aproximaram-se, de alguma forma, da categoria Estratégia em Marketing, conforme aglomerado IV (Figura 4). Embora se tenha encontrado valor de associação altamente significativa, conforme discutido anteriormente, a dispersão entre os pontos do aglomerado IV revela que a associação nele é menor do que as demais representadas nos outros aglomerados.

Recorrendo aos levantamentos para buscar evidências dessa associação, o estudo com um empreendimento de serviço de café colonial, abordando a gestão ambiental como estratégia de marketing, Scharf et al. (2013, p. 240) argumentam que "as estratégias de marketing devem ser desenvolvidas observando o desenvolvimento da atividade turística". A aproximação com essa categoria se deve tanto à adoção de estratégias de marketing pelas empresas, quanto à constatação pelos autores de ausência delas nos ambientes estudados.

Analisando as estratégias de marketing adotadas no setor de serviços e nas agências de viagens, o estudo de Sarquis et al. (2015) constatou várias estratégias adotadas por essas empresas, a exemplo de satisfazer clientes e funcionários, oferecer garantias, atender reclamações no pós-venda, relacionar-se bem com o fornecedor, facilitar acesso aos serviços oferecidos. Por outro lado, em estudo abordando o mercado de vinho-turismo, Koch et al. (2013) constataram que, embora o turismo de vinho seja relevante para os vinhedos no processo de fidelização e manutenção de relacionamentos com os clientes, as estratégias de marketing adotadas pelo vinhedo alemão abordado por eles foram insuficientes nesse sentido. A falta de tempo e a ausência de plataforma de comunicação com os clientes são os principais obstáculos enfrentados por esses comerciantes no processo de implementação de estratégias.

\section{Considerações finais}

O presente estudo buscou, como objetivo geral, analisar a produção científica internacional e nacional relativa aos elementos do composto de marketing adotado em pequenas e médias empresas do trade turístico no período entre 2012 a 2017. Entre os objetivos específicos, buscouse comparar a produção acadêmica internacional e nacional acerca de diferenças metodológicas empregadas. Dessa forma, pode-se citar a predominância do enfoque quantitativo entre os artigos internacionais e do enfoque qualitativo entre os nacionais. Como decorrência disso, o questionário foi o instrumento de pesquisa mais frequente entre o levantamento internacional, assim como as técnicas analíticas quantitativas, tais como estatísticas descritiva, multivariada e bivariada. No que concerne ao levantamento nacional, prevaleceu a entrevista como instrumento de pesquisa e as técnicas analíticas qualitativas, a exemplo da análise de conteúdo.

Ademais, as evidências sinalizaram que as pequenas e médias empresas atuantes no trade turístico continuaram implementando, nos últimos 5 anos, ferramentas dos elementos do marketing mix tradicionais, como o marketing boca a boca e guias turísticos, bem como estão adotando novas outras baseadas na facilidade e no baixo custo das mídias sociais. Destarte, as variáveis do marketing mix mais recorrentes entre o levantamento acadêmico desse estudo foram a promoção (comunicação) e o produto (produtos/ serviços). A variável menos expressiva foi a precificação (preço).

Constatou-se a existência de correspondência categórica entre as teorias utilizadas pelos estudos e a área econômica do turismo abordada por eles. As empresas relacionadas às atividades recreativas, culturais e desportivas do turismo foram associadas à temática do Marketing de Relacionamento. Os meios de hospedagem foram associados às temáticas do Empreendedorismo e do Marketing Digital. Os estudos relacionados à indústria do turismo foram associados às temáticas de Inovação em Marketing e Vantagem Competitiva. Por fim, as agências de viagens e as empresas relacionadas ao ramo de alimentação foram associadas à temática da Estratégia em Marketing.

Como agenda de pesquisa, sublinha-se a necessidade de estudos envolvendo a variável precificação do composto de marketing na literatura concernente às empresas de pequeno porte atuantes no turismo. Além do mais, há necessidade de maior emprego do enfoque misto (combinação das abordagens quantitativa e qualitativa) nessa 
literatura, conforme recomendado por Marujo (2013): tanto nas publicações internacionais (mais inclinada à abordagem quantitativa), quanto nas nacionais (mais inclinada à qualitativa). Por fim, considerando-se o caráter exploratório da técnica estatística da análise categórica de correspondência, são sugeridas investigações aprofundadas acerca das evidências encontradas nesse estudo.

\section{Referências}

Abou-Shouk, M. A., Lim, W. M., \& Megicks, P. (2016). Using competing models to evaluate the role of environmental pressures in ecommerce adoption by small and medium sized travel agents in a developing country. Tourism Management, 52, 327-339.

Abou-Shouk, M., Lim, W. M., \& Megicks, P. (2012). Internet Adoption by Travel Agents: a Case of Egypt. International Journal of Tourism Research, 113(November 2012), 101-113.

Abou-Shouk, M., Lim, W. M., \& Megicks, P. (2016). Using competing models to evaluate the role of environmental pressures in ecommerce adoption by small and medium sized travel agents in a developing country. Tourism Management, 52, 327-339.

Adi, P. H. (2015). Key successful indicators for small businesses' integrated marketing model. International Journal of Applied Business and Economic Research, 13(7), 4815-4829.

Ahmad, S. Z., \& Saber, H. (2015). Understanding marketing strategies with particular reference to small- and medium-sized hotel businesses in the United Arab Emirates. Tourism and Hospitality Research, 15(2), 115-129.

Araújo, R. F., \& Alvarenga, L. (2011). A bibliometria na pesquisa científica da pós-graduação brasileira de 1987 a 2007. Revista Eletrônica de Biblioteconomia, 16 (31), 51-70.

Awang, K. W., Aziz, Y. A., \& Samdin, Z. (2012). The growth of micro, small, and medium-sized hotel enterprises: The roles of the state. Arab World Geographer, 15(4), 302-317.

Barbosa, F. S. (2013). Planejamento Estratégico Para Eventos: Um Estudo De Caso Das Estratégias De Marketing Utilizadas Pela Oktoberfest De Santa Cruz Do Sul / Rs. Revista de Cultura E Turismo, (2008), 1-16.

Barbosa, F. S. (2014). Distribuição eletrônica na hotelaria: um estudo de caso do Hotel Casa de Praia, Fortaleza (CE). Revista Brasileira de Ecoturismo, 7(3), 539-550.

Bonillo, M. A., Fernandez, R., \& Taulet, A. (2012). Online value creation in small service businesses: the importance of experience valence and personal values. The Service Industries Journal, 32(15), 2445-2462.
Brasil. (2007). Programa de Regionalização do Turismo - Roteiros do Brasil: Módulo Operacional 7.

CAPES. (2014). Classificação da produção intelectual. Retrieved June 01, 2017, from http://www. capes.gov.br/avaliacao/instrumentos-de-apoio/ classificacao-da-producao

Carlisle, S., Kunc, M., Jones, E., \& Tiffin, S. (2013). Supporting innovation for tourism development through multi-stakeholder approaches: Experiences from Africa. Tourism Management, 35, 59-69.

Chen, H.-L., \& Mathews, S. (2014). Experiential Brand Deployment: Improving Tourism Brand Evaluations. Journal of Hospitality \& Tourism Research, 35, 59-69.

Corrêa, C. H. W. (2014). e-Marketing das Estâncias Hidrominerais do estado de São Paulo. Revista Turismo em Análise, 25(2), 476-496.

Cosma, S., Paun, D., Bota, M., \& Fleseriu, C. (2014). Innovation - A Useful Tool in the Rural Tourism in Romania. Procedia - Social and Behavioral Sciences, 148, 507-515.

Favre-Bonté, V., \& Tran, S. (2015). The contribution of the Internet to the strategic positioning of small businesses in the tourism industry. International Journal of Entrepreneurship and Small Business, 25(3), 296-313.

Fernandes, S., Belo, A., \& Castela, G. (2016). Social network enterprise behaviors and patterns in SMEs: Lessons from a Portuguese local community centered around the tourism industry. Technology in Society, 44, 15-22.

Field, A. P. (2009). Discovering statistics using SPSS. London, England: SAGE.

Figueiredo, A., Grande, R., Christine, J. (2017). As contribuições da Internet nos efeitos da sazonalidade: um estudo realizado em um hotel de pequeno porte. Revista Brasileira de Gestão e Inovação, $4(2), 42-63$.

Firat, A., Turker, G. O., \& Metin, I. (2014). Specification of target market in small and medium scale accomadation businesses: A study on boutique hotels operating in city of mugla. Tourismos, 9(2), 279-299.

Hair, Joseph (2010). Multivariate data analysis. 7th ed. Upper Saddle River: Prentice Hall.

Jaafar, M. (2012). Entrepreneurial marketing and accommodation businesses in East Peninsular Malaysia. Tourism and Hospitality Research, 12(2), 89-100.

Jaafar, M., Aziz, A., \& Sukarno, S. (2012). Tourism Marketing: An Overview of Small and Medium Budget Hotels (SMBHs). Asia Pacific Journal of Tourism Research, 17(1), 1-13.

Jacobsen, D. (2017). Tourism enterprises beyond the margins: the relational practices of Aboriginal and 
Torres Strait Islander SMEs in remote Australia. Tourism Planning E Development, 14(1), 31-49.

Koch, J., Martin, A., \& Nash, R. (2013). Overview of perceptions of German wine tourism from the winery perspective. International Journal of Wine Business Research, 25(1), 50-74.

Krohling, A. B., \& Pelissari, A. S. (2013). Marketing de Relacionamento: um estudo em pousadas de Marechal Floriano - ES. Revista Turismo Em Análise, 24(2), 325-353.

Marcondes, D., \& Corrêa, C. (2016). Tecnologias da informação e comunicação na promoção de empreendimentos locais nas comunidades tradicionais caiçaras de Ilhabela (SP). Caderno Virtual de Turismo, 16(2), 168-182.

Marsilio, M., \& Vianna, S. L. G. (2014). Agências de Viagens e Turismo e o Impacto da Internet: um Estudo Bibliométrico. Turismo - Visão e Ação, 16(2), 450-476.

Marujo, N. (2013). A pesquisa em turismo: reflexões sobre as abordagens qualitativa e quantitativa. Revista de Investigación en Turismo e Desarollo Local, 6(2013), 1-16.

Mbatha, B. (2013). Exploring the potential of electronic commerce tools in South African SME tourism service providers. Information Development, 29(1), $10-23$.

McCarthy, E. (1960). Basic Marketing: A Managerial Approach. England: R.D. Irwin.

Mizrachi, I., \& Sellitto, C. (2015). Building a Facebook Strategy: Some Insights From Australian Accommodation Small Tourism Enterprises (STEs). Journal of Quality Assurance in Hospitality E Tourism, 16(1), 63-79.

Moral, P., Gonzalez, P., \& Plaza, B. (2014). Methodologies for monitoring website performance. Online Information Review, 38(4), 575-588.

Nakara, W. A., Benmoussa, F. Z., \& Jaouen, A. (2012). Entrepreneurship and social media marketing: evidence from French small business. International Journal of Entrepreneurship and Small Business, 16(4), 386.

Niedersberg, J. J., \& Mondo, T. S. (2016). A inovação nos meios de hospedagem na praia da Armação - sul da ilha de Santa Catarina Innovation in hotels of Armação beach - Florianópolis / Brazil. Observatório de Inovação do Turismo, X (2).

Oliveira, R., \& Felizola, M. P. M. (2012). Ações de marketing nas pequenas e médias empresas do setor hoteleiro em Aracaju. Revista Temática, VIII (8), 1-14.

Pechlaner, H., Herntrei, M., Pichler, S., \& Volgger, M. (2012). From destination management towards governance of regional innovation systems - The case of South Tyrol, Italy. Tourism Review, 67(2), 22-33.
Romolini, A., Fissi, S., \& Gori, E. (2017). Integrating territory regeneration, culture and sustainable tourism. The Italian albergo diffuso model of hospitality. Tourism Management Perspectives, 22, 67-72.

Rossetto, A. M. (2014). A percepção dos gestores quanto às práticas sustentáveis implantadas em meios de hospedagem de pequeno porte. Revista de Turismo Contemporâneo. 74-94.

Ruiz, M. a, Greco, O. T., \& Braile, D. M. (2009). Fator de impacto: importância e influência no meio editorial, acadêmico e científico. Revista Brasileira de Hematologia e Hemoterapia, 24(3), 273-278.

Sacramento, P. M., \& Teixeira, R. M. (2014a). Adoção de inovações em empresas de pequeno e média portes: estudo de casos múltiplos em negócios hoteleiros na cidade de Aracaju. Organizações em Contexto, 10(19), 1-30.

Sacramento, P. M., \& Teixeira, R. M. (2014b). Implementação de ações inovadoras e empreendedorismo: estudo de múltiplos casos em empresas hoteleiras de. Caderno Virtual de Turismo, 14(2), 183-203.

Sampieri, R., Fernández, C., Baptista, P. (2010) Metodología de la investigación (5ta. ed.). D.F., México: McGraw Hill.

Santos, A. V. dos, \& Santos, M. T. dos. (2011). Marketing Turístico - Curso Técnico em Hospedagem. Centro de Educação Tecnológica do Amazonas CETAM, 51p.

Sarquis, A. B., Pizzinatto, N., Giuliani, A. C., \& Pontes, A. S. M. (2015). Estratégias de marketing: Estudo no setor de agências de viagens e turismo. Revista Brasileira de Pesquisa em Turismo, 9(2), 298-320.

Scharf, E. R., Fernandes, J., \& Orlandi, O. (2013). Gestão ambiental como estratégia de marketing em uma empresa de turismo rural. Revista Turismo Visão e Ação, 15(2), 226-243.

Schwarzbach, L., Deretti, S., \& Ferreira, V. (2014). Orientação para o mercado: a adoção do conceito de marketing nas pousadas do município de Morretes. Revista Eletrônica de Administração e Turismo, 4(2), 336-351.

SCImago. (2007). SJR — SCImago Journal \& Country Rank. Retrieved July 21, 2015, from http://www. scimagojr.com

Sebrae. (2013). Anuário do trabalho na micro e pequena empresa 2013. Serviço Brasileiro de Apoio às Micro e Pequenas Empresas. Brasília: Sebrae/Dieese.

Seilov, G. A. (2015). Does the adoption of customer and competitor orientations make small hospitality businesses more entrepreneurial? International Journal of Contemporary Hospitality Management, 27(1), 71-86.

Shah, S. M. A., El-Gohary, H., \& Hussain, J. G. (2015). An Investigation of Market Orientation (MO) and Tourism Small and Medium-Sized Enterprises' (SMEs) Performance in Developing Countries: A 
Review of the Literature. Journal of Travel $\&$ Tourism Marketing, 32(8), 990-1022.

Souza, A. G. De, \& Kovacs, M. H. (2009). Marketing Turístico E Promoção: Uma Análise Sobre As Ações De Comunicação Empreendidas Pela Empresa De. Turismo Visão e Ação, 11(2), 201-217.

Suzuki, G. da S., Burkowski, R., \& Mesquita, J. M. (2015). Eventos Gastronômicos e Estratégias de Marketing: O Festival Comida Di. Revista Rosa Dos Ventos - Turismo e Hospitalidade, 7(2), 242-256.

Tachizawa, T., Pozo, H., \& Vicente, A. J. (2013). O uso de tecnologias da informação em hotéis de pequeno porte: um estudo multicaso. Revista Organizações em Contexto, 9(17), 31-57.

Teixeira, R. M. (2014). Adoção de inovações em empresas de pequeno e médio portes: estudo de casos múltiplos em negócios hoteleiros na cidade de Aracaju. Organizações em context, 10(19), 1-30.

Tejada, P., \& Moreno, P. (2013). Patterns of innovation in tourism "Small and Medium-size Enterprises". The Service Industries Journal, 33(7-8), 749-758.

Tomazzoni, E. L., Bock, I. A., \& Simon, S. (2012). Caminhos da Colônia: Turismo Rural na Serra. Revista Rosa dos Ventos, II (4).
Zagheni, E. S. da S., \& Luna, M. M. M. (2011). Canais de distribuição do turismo e as tecnologias de informação: um panorama da realidade nacional. Revista Científica Eletrônica de Engenharia de Produção, 11(2), 476-502.

Zaidan, E. (2016). Analysis of ICT usage patterns, benefits and barriers in tourism SMEs in the Middle Eastern countries: The case of Dubai in UAE. Journal of Vacation Marketing. 1-16.

Contribuição dos autores na construção do artigo:

Miranda Júnior: Promoveu a ideia sobre o tema entre os demais autores; realizou varredura em bases de dados; compilou artigos; contribuiu para a fundamentação teórica e discussões do artigo; participou das análises estatísticas.

Sousa: Auxiliou na varredura em bases de dados; contribuiu para a fundamentação teórica e discussões do artigo.

Demo: Realizou a revisão do artigo; realizou correções metodológicas e estatísticas; alinhou o trabalho ao campo do marketing nas discussões do artigo. 